\title{
Anticipatory and Post Hoc Cushioning Strategies: Optimism and Defensive Pessimism in "Risky" Situations ${ }^{1}$
}

\author{
Julie K. Norem ${ }^{2}$ and Nancy Cantor \\ University of Michigan
}

The concept of cognitive strategies is proposed as a model for the process by which individuals cushion themselves against threats to self-esteem in "risky" situations. Two strategies are discussed. The first is defensive pessimism, an anticipatory strategy that involves setting defensively low expectations prior to entering a situation, so as to defend against loss of selfesteem in the event of failure. The second is an optimistic strategy, where expectations are high at the outset, and post hoc restructuring of the situation is done when the outcome is known. Expectations about performance on an anagram task were collected from prescreened optimistics and defensive pessimists. After completion of the task, subjects were given false failure or success feedback. A posttest measuring self-reported satisfaction, feelings of control, and performance evaluations was administered. As predicted, subjects selected for defensive pessimist attitudes expected to perform significantly worse than did those selected for optimistic attitudes, even though there was no difference in actual performance. Moreover, optimists demonstrated attributional egotism in claiming significantly more control over their performance in the success condition than in the failure condition. Pessimists did not show this pattern. The data provide evidence of post hoc cushioning efforts among optimists, whereas defensive pessimists seem to be cushioned by their initial structuring of the situation. It is argued that

'The authors would like to thank Aaron Brower, Nancy Genero, Hazel Markus, Paula Niedenthal, Carolin Shower, Steve Hollon, and two anonymous reviewers for their helpful comments on earlier drafts of this paper.

${ }^{2}$ Address all correspondence to Julie K. Norem, Department of Psychology, University of Michigan, Ann Arbor, Michigan 48109. 
these strategies can be understood as motivated attempts to solve the "problem" of a "risky" situation.

KEY WORDS: strategies; defensive pessimism; optimism.

Interpretations of situations are frequently assumed to guide the planning and execution of behavior (Kelly, 1955/1963; Goldfried, Padawer, \& Robins, 1984; Mischel, 1973). To understand how people interpret important situations, it seems reasonable to consider those situations as presenting problems to be solved (Cantor \& Kihlstrom, 1985). In order to solve the problem of a given situation through appropriate and effective action, individuals must (1) understand the problem so as to determine what they can expect to encounter, (2) plan a solution to the problem, which includes selection of appropriate behaviors, (3) expend the effort necessary to implement the behaviors selected, and (4) monitor the impact and effectiveness of that behavior (D'Zurilla \& Goldfried, 1971; McFall, 1982; Spivak, Platt, \& Shure, 1976).

It is clear, however, that many of the complex situations of interest to psychologists present problems that are generally ill-defined, as opposed to well-defined (Cantor, 1984; Kihlstrom, 1984). To the extent that this is true, there should be considerable variation in the framing or representation of the problems in a given situation. It then becomes necessary to determine what factors influence how different individuals construct the "problem" in a situation differently. The problem-solving cycle involves continual reference to the appropriateness or effectiveness of behaviors relative to a particular desired outcome or goal. It seems, therefore, that the personal goals or objectives of the individual may have considerable impact on the framing of the problem, and thus on the entire problem-solving cycle (Higgins, McCann, \& Fondacaro, 1982).

This paper will consider how individuals go about solving the problems presented by situations that are "risky" (i.e., that can be interpreted as presenting a potential threat to self-esteem), and dealing with the potential success or failure of their solutions. Specifically, discussion will center on two particular cognitive strategies that people may use to solve the problems presented by a situation in which successful performance is desired. Often, in situations where success is possible, there is a congruent possibility of failure. Starting with this premise, the paper will focus on ways of constructing the problem of these "risky" situations so as to cushion the impact of potential failure. 


\section{ANTICIPATORY STRATEGIES}

The construction of a situation involving the possibility of success or failure depends to some extent on both the degree to which individuals fear potential failure, and the strength of their desire for success. If the goal of avoiding failure is as important as, or more important than, the goal of achieving success in a given situation, the individual should construct the situation accordingly and select a strategy that increases the probability of avoiding failure. For example, Jones and Berglas (1978) present a "self-handicapping" strategy whereby individuals faced with a threat to self-esteem, like a risky achievement situation, withdraw effort in order to avoid the implications about competence that may result from failure. Anticipating a threat to selfesteem, they restructure the attributional situation so as to minimize that threat. By withdrawing effort (or "sabotaging" themselves), self-handicapping persons avoid negative ability attributions. Failure is simply attributed to lack of effort, which is presumably less "incriminating" than lack of ability, because it is an unstable cause that is potentially under the control of the individual (Weiner \& Kukla, 1970). In the unlikely event of success, where the self-handicapper has succeeded despite lack of effort, the implication is that he is exceptionally able.

There are three important points to be noted about the self-handicapping strategy. First, the structure of the situation as one with important attributional implications is done by the individual before entering the situation. Second, Jones and Berglas argue that individuals using the strategy do so because they have an excessive fear of the competence implications of failure. Third, for the strategy to succeed in protecting self-esteem and competence beliefs, the individual must see the attributional implications of the situation as more important than the failure or success of the performance itself. That is, there is more emphasis on the problem of protecting self-esteem than on the goal of achieving success.

Alternative constructions of the same situation are required when personal goals conflict -i.e., when there is a fear of failure and a strong desire for success. In this situation, a strategy called "defensive pessimism" may be used. By this is meant a discounting of past successes, and the lowering of expectations prior to entering a situation, in order to prepare or defend against excessive loss of self-esteem should failure occur.

This strategy should be used by individuals faced with a performance situation in which failure is threatening to self-esteem or self-image and success is highly desirable and important to the individual. Thus, unlike the self- 
handicapper, for the individual utilizing this strategy, the attributional implications are important, but they do not override the significance of the performance itself. The defensive pessimist, therefore, does not feel he can afford to jeopardize his chances of success by withdrawing effort. However, he is still faced with conflict between his wish to avoid failure, which tempts him away from the situation, and his desire for success, which pushes him into the situation. The problem, as constructed by the defensive pessimist, is to overcome the immobilization that results from conflicting goals (Atkinson \& Litwin, 1960). His solution is to prepare himself for failure by defensively setting low expectations in advance. By "playing through" potential bad outcomes before they occur, the defensive pessimist gains some degree of control over his anxiety. It's as if he braces himself against the impact of failure by dwelling on the possibility. ${ }^{3}$

Though this strategy should prepare one for failure, we do not expect the defensive pessimist to be pleased with failure. With the situation structured as described, the impact of failure on self-esteem should be cushioned to the extent that the defensive pessimist should not need to engage in protective restructuring after the fact. His prior structuring of the situation, not the eventual outcome, should determine feelings of control. Thus, we do not expect defensive pessimists to deny control over, or responsibility for, failure, or to claim significantly more control over success than over failure.

\section{A "POST HOC" STRATEGY}

In contrast to the defensive structuring of a situation prior to entering, it is also possible to cushion oneself against failure after that failure has occurred. Reflecting this alternative construction of the same situation, we hypothesize a particular optimistic strategy that builds on research into "illusory glow" cognitive biases found among "normal" (i.e., nondepressed) college student subjects (see Greenwald, 1980, for a review). These biases can be seen as part of a general strategy whereby the goal of maintaining or enhancing self-esteem is translated into the behavior found in the literature on selfserving biases. We hypothesize that the optimist does not see advance protection against failure as the primary problem presented by achievement situations. The main problem for the optimist is trying to achieve success from

\footnotetext{
${ }^{3}$ We assume that the same "objective" situation, e.g., a final exam, may be interpreted as one appropriate for self-handicapping or defensive pessimism, depending on the individual. Though we currently have no evidence on this matter, it seems reasonable to suspect that the intensity of fear of failure may be one variable that determines selection of the self-handicapping strategy over the defensive pessimist strategy in a given situation.
} 
the outset; he deals with failure when it happens. The optimist, for whatever reason, is not particularly fearful of failure and is thus able to "trust" his past base rate when setting expectations. $\mathrm{He}$ is, however, motivated to "cushion" himself if and when failure does occur. Not having prepared himself in advance, he relies on post hoc attributions to protect his self-esteem. If he fails, he is prepared to maintain his self-esteem by denying that he had control over the situation. These attributions are not limited by his prior structuring of the situation, as is the case for defensive pessimists.

Assuming these descriptions of the strategies, we make two major predictions about the differences between the behavior of the "normal" optimists and that of "normal" persons using the defensive pessimist strategy in risky achievement situations:

First, we expect pessimists to have lower expectations than optimists about an upcoming performance, even given similar past base rates. This lowering of expectations is the initial defensive maneuver.

Second, pessimists faced with failure in a given situation should be cushioned by the strategy; i.e., they should be able to acknowledge control over their performance. Pessimists have presumably cushioned themselves prior to entering a situation by emphasizing the probability of failure. In contrast, the optimists can be expected to use "illusory glow" cognitive biases, such as denial of control over failure, after the fact (Alloy \& Abramson, 1979). This strategy allows optimists to alter the attributional implications of failure and thus "cushion" the impact of negative outcomes. Clearly, the argument is not that either optimists or pessimists are happy with failure. Rather, we predict that, for optimists, perception of control will be significantly related to satisfaction and performance evaluation and thus should vary as a function of outcome. In contrast, for the pessimists, feeling of control should not be related to satisfaction and performance evaluation since they do not need to deny control over failure after the fact in order to protect their self-esteem.

\section{METHOD}

\section{Overview}

In order to begin to test these hypotheses, we prescreened subjects for optimistic and defensively pessimistic attitudes. The prescreening resulted in subjects chosen for two groups: those thought to use optimistic strategies, and those thought to use defensively pessimistic strategies in achievement situations. These subjects were asked to predict their performance on an 
anagram test, and then to take the test. Half the subjects within each strategy grouping were given false feedback indicating failure; half were given false feedback indicating success. A posttest assessing self-evaluation of performance, satisfaction, and attributions about the situation was administered after two anagram blocks. Subjects were then debriefed about the false feedback, and a third set of predictions was gathered to assess feedback perseverance.

\section{Prescreening and Subjects Selection}

A total of 1,027 subjects from an introductory psychology subject pool were administered a prescreening questionnaire designed to identify selfreported use of optimistic or defensively pessimistic strategies in an academic domain. Subjects indicated to what degree a series of eight statements describing characteristics of either optimism or defensive pessmism was characteristic of their thoughts and behavior in academic situations (see Table I). An "optimism-pessimism" score was then computed for each subject by subtracting the sum of their endorsement of four pessimistic items (questions 1, 4, 6 , and 8) from the sum of their endorsements of four optimistic items (questions, 2, 5, 7, and 9). Analyses of the total prescreened sample showed that items $1,2,3$, and 6 were most predictive of the total optimism-pessimism scores (item-by-item correlations with total score, $r$ 's $>.57$ ).

Subjects also indicated which of a series of general strategy profiles best described them. There were four profiles, which consisted of general descriptions of strategies or approaches. The profiles described an optimistic outlook, where an individual acknowledges generally positive past experiences and expects positive outcomes in the future; a defensive pessimistic outlook, where positive past experience is recognized, but expectations for future outcomes

Table I. Optimism-Pessimism Prescreening Questionnaire

Rate each of the following items using the scale below to indicate how true it is of you.
Not at all
true of me


are low; a "regular" pessimistic outlook, where past experience is considered negative and more negative outcomes are expected; and an "unjustified" optimistic outlook, where past experience is bad, but expectations for the future are good. The "regular" pessimistic outlook was seen as similar to that of a depressive, and was included specifically to distinguish between optimists and defensive pessimists on the one hand and depressives on the other. In addition, we included only those subjects who strongly endorsed question 3 in Table I; "I've generally done pretty well in academic situations in the past," thus choosing subjects who specifically acknowledged a high past base rate.

The average scores on each item of the prescreening, for the entire sample and for the selected groups of optimists and pessimists, are included in Table II. We selected individuals from the "pessimistic" and "optimistic" tails of the distribution of pessimists scores, who also gave relatively strong endorsements of the correpsonding profiles, and who strongly endorsed question 3. Subjects selected as pessimists had an average rank of 1,009 (out of 1,027 ) for their optimism-pessimism scores (where a lower score means more pessimism), and the optimists selected had an average rank of 22. Moreover, to have some control for past experience and ability, we selected only subjects with grade point average of 3.0 or higher. There was no significant difference in GPA for optimists and pessimists $(\bar{X}=3.34$, and $\bar{X}=3.23$, respectively, $F(1,63)=1.49$, n.s.).

It should be noted that the items included in the prescreening are specifically concerned with academic situations. This is because defensive pessimism and optimism as referred to here are not considered to be broad cognitive traits. They are described as strategies precisely because it is believed that they can be used selectively (i.e., strategically) in different situations, depending on context-specific goals. Indeed, there is preliminary evidence

Table II. Ratings from Prescreening Questions

\begin{tabular}{|c|c|c|c|c|c|c|}
\hline \multirow[b]{2}{*}{ Question No. } & \multicolumn{2}{|c|}{$\begin{array}{c}\text { Entire Sample } \\
(N=1,027) \\
\end{array}$} & \multicolumn{2}{|c|}{$\begin{array}{l}\text { Optimists } \\
(N=35)\end{array}$} & \multicolumn{2}{|c|}{$\begin{array}{l}\text { Pessimists } \\
(N=34)\end{array}$} \\
\hline & Mean & $S D$ & Mean & $S D$ & Mean & $S D$ \\
\hline 1 & 4.79 & 2.68 & 2.09 & 1.27 & 8.51 & 2.11 \\
\hline 2 & 7.34 & 2.31 & 9.95 & .90 & 3.65 & 1.46 \\
\hline 3 & 8.64 & 1.86 & 9.95 & .84 & 9.12 & 1.55 \\
\hline 4 & 6.14 & 2.99 & 2.74 & 1.21 & 8.98 & 2.40 \\
\hline 5 & 7.82 & 2.59 & 9.97 & 1.06 & 5.40 & 3.12 \\
\hline 6 & 5.72 & 2.86 & 2.58 & 1.18 & 8.47 & 2.30 \\
\hline 7 & 7.57 & 2.52 & 0.97 & 1.91 & 6.23 & 3.02 \\
\hline 8 & 8.90 & 2.23 & 6.39 & 2.74 & 9.98 & 1.12 \\
\hline 9 & 9.83 & 1.46 & 10.16 & 1.05 & 8.98 & 2.36 \\
\hline $\begin{array}{l}\text { Total optimism- } \\
\text { pessimism score }\end{array}$ & 7.02 & 9.42 & 25.35 & 3.45 & -11.67 & 5.29 \\
\hline
\end{tabular}


that indicates that subjects using defensive pessimism in social contexts do not necessarily use it in academic domains. An analogous prescreening for optimism and defensive pessimism in social situations was done on the same sample discussed here, in order to select subjects for a complementary study. A moderate correlation was found between self-reported use of a particular strategy in one domain and the other $(r=.38)$, but the overlap between the situations was far from complete.

\section{Experimental Design}

Sixty-nine prescreened subjects -35 optimists and 34 pessimists - participated in the experiment. Subjects within the pessimistic and optimistic strategy groupings were randomly assigned to either a "success" or "failure" feedback condition. The 2 (strategy) $\times 2$ (feedback condition) design resulted in four cells: failure pessimists, failure optimists, success pessimists, and success optimists.

The study was run with subjects, in groups of four or five, who were told that the study was concerned with "what kind of abilities are necessary for different tasks." It was expected that this explanation, in conjunction with the description of the task, would serve as an achievement induction that would prime performance goals connected with academic situations, and the risks congruent with attempts to achieve those goals (Weiner, 1965).

The anagram task was described, and subjects were asked to predict how well they thought they would perform on the task. The study was set up so that subjects gave initial predictions about their expected performance (Time 1), took the timed anagram test, and were given false feedback. After a distraction task, new predictions were collected and a second test was given (Time 2). Subjects were then asked to complete a posttest questionnaire, after which they were debriefed about the false feedback. A third round of predictions was then collected to assess feedback perseverance (Time 3 ).

After the first set of predictions was gathered, subjects were given 2 minutes to solve as many anagrams as they could on each trial. After 2 minutes, subjects turned in their tests, which were ostensibly scored by the experimenter. Each subject was then handed a bogus feedback sheet, with false norms and the subject's (false) score. Subjects were unable to see one another's scores. In the success condition the subject's scores were an average of 10 percentage points higher than the "norms," and in the failure condition the scores were an average of 10 percentage points lower than the "norms." The feedback given after the second anagram performance was the same as that given after the first performance. 


\section{Dependent Measures}

The dependent measures included the predictions gathered at Time 1 (before feedback), Time 2 (after feedback), and Time 3 (after debriefing). For these predictions, subjects were asked to rate how well they thought they would do in comparison to various peer reference groups on a scale from 1 (very poorly) to 11 (very well). The reference groups included the general population, high school graduates, average college students, average University of Michigan students, and students with the same GPA.

The posttest questionnaire included self-ratings of the first and second trials anagram performances, as well as an overall performance rating. Performance evaluation ratings were on a scale from 1 (very poorly) to 11 (very well). Subjects also rated their satisfaction with and feelings of control over each performance. The ratings were made on a scale from 1 (unsatisfied or no control), to 7 (satisfied or total control).

\section{RESULTS}

We expected to find that, throughout the experiment, the pessimists' predictions would be lower than the optimists' in a given condition. There should also be evidence of post hoc cushioning efforts among the optimists, since they deny control over failure and accept responsibility for success. We did not expect to see this pattern in the pessimists, who have presumably cushioned themselves against failure before entering the situation by "taking control," and thus should not alter their perceptions of control after the outcome is known.

Since, across all subjects, prediction of performance relative to any particular reference group correlated highly with prediction relative to all the other reference groups (average $r=.73$ ), the predictions were averaged across reference groups for each subject. Thus, a prediction score was created for each subject for Time 1, Time 2, and Time 3 (see Table III). Figure 1 shows the mean prediction scores at all three points. A three-way (strategy $\times$ condition $\times$ time) ANOVA, with repeated measures on the time factor, performed on these prediction scores shows a significant difference in expectations between optimists and pessimists that remains throughout the experiment $(F(1,65)=5.07, p=.03)$. This analysis also reveals a condition (success or failure) main effect $(F(1,65)=4.40, p=.04)$. There was also a condition $\times$ time interaction effect, indicating significant change in predictions across Time 1 , Time 2 , and Time 3 , depending on condition assignment $(F(2,130)=8.32, p=.000)$. 

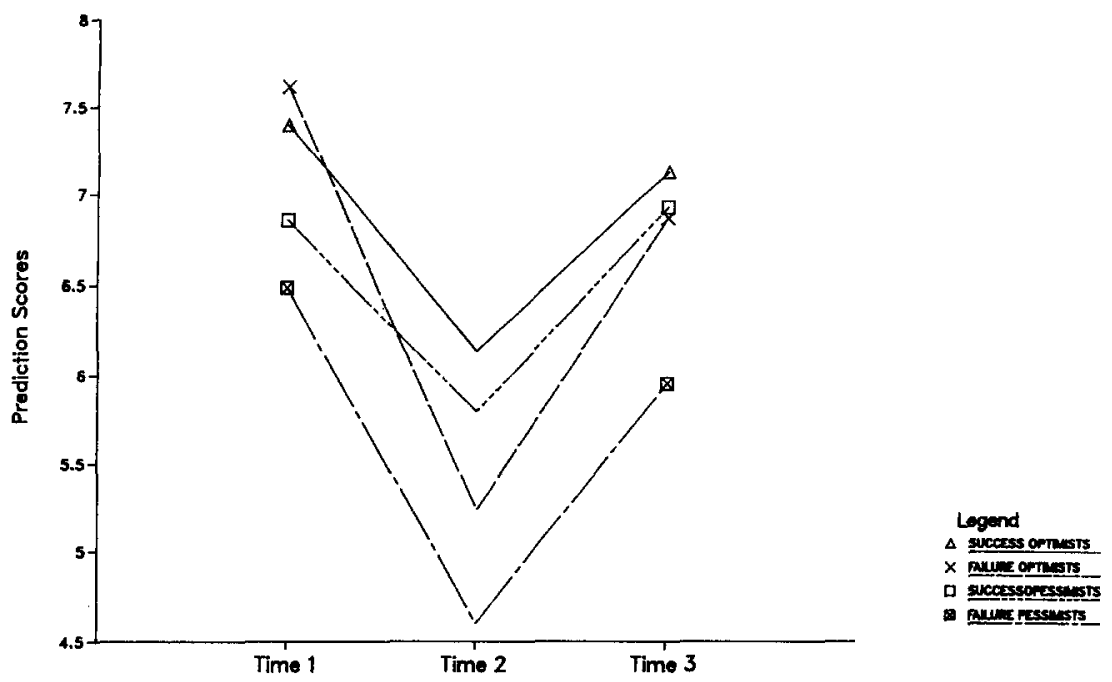

Fig. 1. Prediction scores at Time 1, Time 2, and Time 3: success optimists, failure optimists, success pessimists, and failure pessimists.

Given these results from the overall ANOVA, the mean prediction scores at Time 1 for optomists and pessimists were compared (see Table III). Optomists predicted that they would do significantly better than pessimists predicted they would do $(F(1,68)=6.15, p=.02)$. This initial difference between strategy groups is in the predicted direction and provides validation of the prescreening procedure. The pessimists' lower expectations for their performance exist even though both groups have had similar (high) past rates of success in the academic domain. Moreover, means for the actual scores of all four cells on both the Time 1 and Time 2 tests (see Table III) show

Table III. Prediction Scores, Actual Scores, and GPAs

\begin{tabular}{|c|c|c|c|c|c|c|c|c|}
\hline & \multicolumn{4}{|c|}{ Optimists } & \multicolumn{4}{|c|}{ Pessimists } \\
\hline & \multicolumn{2}{|c|}{ Success } & \multicolumn{2}{|c|}{ Failure } & \multicolumn{2}{|c|}{ Success } & \multicolumn{2}{|c|}{ Failure } \\
\hline & Mean & $S D$ & Mean & $S D$ & Mean & $S D$ & Mean & $S D$ \\
\hline \multicolumn{9}{|l|}{$\begin{array}{l}\text { Prediction } \\
\text { scores }\end{array}$} \\
\hline Time 1 & 7.40 & 1.16 & 7.62 & 1.66 & 6.86 & 1.40 & 6.49 & 1.38 \\
\hline Time 2 & 6.14 & 1.12 & 5.24 & 1.65 & 5.80 & 1.80 & 4.60 & 1.14 \\
\hline Time 3 & 7.14 & 1.17 & 6.88 & 1.86 & 6.94 & 1.14 & 5.96 & 1.53 \\
\hline \multicolumn{9}{|c|}{ Actual scores } \\
\hline Time 1 & 39.39 & 8.99 & 40.82 & 17.58 & 40.65 & 16.34 & 36.77 & 13.18 \\
\hline \multirow[t]{2}{*}{ Time 2} & 36.06 & 15.06 & 37.00 & 16.84 & 37.35 & 14.10 & 30.41 & 12.54 \\
\hline & \multicolumn{2}{|c|}{$N=18$} & \multicolumn{2}{|c|}{$N=17$} & \multicolumn{2}{|c|}{$N=17$} & \multicolumn{2}{|c|}{$N=17$} \\
\hline
\end{tabular}


no significant difference in performance (all $F_{\mathrm{S}}<1$ ). This gives additional support to our claim that differences in ability do not account for the difference in expectations between optimists and pessimists.

Information about the condition manipulation is provided by a threeway ANOVA of prediction scores at Time 1 and Time 2. This analysis shows a strategy main effect $(F(1,65)=4.87, p=.03)$, a condition main effect $(F(1,65)=3.53, p=.06)$, and a time main effect $(F(1,65)=113.61, p$ $=.000)$. Interestingly, as can be seen in Figure 1, all the subjects lowered their predictions at Time 2, relative to Time 1. Apparently all the subjects found the test more difficult or involved than they had anticipated, and lowered their predictions accordingly. Evidence that the feedback manipulation was effective is apparent in the time $\times$ condition interaction effect $(F(1$, $65)=18.40, p=.000$ ). This effect is accounted for by significant differences between success subjects' expectations and failure subjects' expectations at Time 2 (after receiving the first feedback) $(F(1,68)=12.20, p=.000$ ), a difference that does not exist at Time $1(F<1)$.

Finally, prediction scores in both conditions changed somewhat after debriefing, as evidenced by Figure 1. A three-way repeated-measures ANOVA of the Time 2 and Time 3 prediction scores reveals main effects for strategy $(F(1,65)=3.84, p=.05)$, condition $(F(1,65)=9.02, p=.004)$, and time (Time 2 to Time $3,(F(1,65)=113.61, p=.000)$. The time $\times$ condition interaction term is not significant $(F<1)$. Thus, failure subjects' scores at Time 3 are still significantly less than success subjects' scores at Time 3 ( $F(1$, 68) $=4.54, p=.04)$.

Our second hypothesis was that pessimists would not alter their construction of the situation after the fact as a function of feedback. In contrast, we expected optimists to "revise" their perceptions of the situation according to the feedback they received, and thus to feel less control in the failure condition than in the success condition. Optimists should be using their attributions of control to explain their lack of satisfaction and low performance in the failure condition in ways that do not implicate competence, (i.e., so self-esteem is not threatened). As part of the greater satisfaction felt in the success condition, the optimists should be willing to accept more responsibility for their performances. In contrast, the pessimists have already constructed the situation in a self-protective light prior to entering, and thus should not "rework" it in order to control attributions.

In fact, examination of the correlations among the posttest dependent measures shows a significant relationship between satisfaction and control, and between perceived performance and control among the optimists $(r=$ .68 , and $r=.52$, respectively, for the first trial; $r=.69$ and $r=.39$ for the 2 nd trial). In contrast, there is no relationship between feelings of control and either satisfaction or perceived performance for the pessimists $(r$ 
Table IV. Means for Satisfaction, Control, and Performance Evaluations for First and Second Anagram Performance ${ }^{a}$

\begin{tabular}{cccccc}
\hline & \multicolumn{2}{c}{ Optimists } & & \multicolumn{2}{c}{ Pessimists } \\
\cline { 2 - 3 } \cline { 5 - 6 } Posttest ratings & Success & Failure & & Success & Failure \\
\hline Satisfaction & & & & & \\
1st trial & 4.66 & 3.17 & & 4.70 & 2.82 \\
2nd trial & 4.72 & 3.17 & & 4.47 & 2.82 \\
Control & & & & \\
1st trial & 5.00 & 3.05 & & 4.88 & 4.00 \\
2nd trial & 4.83 & 3.41 & & 4.64 & 4.18 \\
Performace & & & & \\
1st trial & 6.94 & 5.23 & & 6.52 & 4.00 \\
2nd trial & 6.72 & 4.94 & & 6.29 & 4.06 \\
\hline
\end{tabular}

${ }^{a}$ Ratings were made after false feedback was given, before debriefing.

$=.11$ for control and satisfaction; $r=.08$ for control and performance for the 1st trial; $r=.18$ and $r=.03$ for the 2nd trial).

Thus, we find evidence of post hoc cushioning by optimists that is not found for pessimists. Success optimists report feeling significantly more in control than failure optimists for both the first and second anagram trials $(F(1,34)=14.50, p=.0006 ; F(1,34)=8.49, p=.006)$. There is no significant difference, however, between pessimists' reports of control across success and failure feedback ( $F<1$, for both trials). Table IV shows the mean satisfaction, control, and performance ratings in all four cells, for both anagram performances. Optimists are showing attributional egotism by taking responsibility for success and denying blame for failure. Pessimists are not showing this trend. Presumably this indicates that pessimists are not cushioning failure by denying that they had control but, as a function of their anticipatory structuring of the situation, are accepting responsibility for both success and failure.

Further supporting our contention that failure pessimists are cushioned without using the post hoc optimistic strategy, the data reveal no significant differences in satisfaction between optimists and pessimists in the failure condition, for either their first or their second anagram performance $(F s<$ 1 , n.s.). Thus, failure pessimists are no less satisfied than failure optimists (or no more dissatisfied), even though they are not doing post hoc cushioning.

Finally, both optimists and pessimists are accepting the success feedback, as indicated by their reported feelings of satisfaction. That is, both optimists and pessimists reported feeling significantly more satisfied in the success condition than in the failure condition $(F(1,65)=24.05, p<.001$, 1st trial; $F(1,65)=25.32, p<.001,2$ nd trial). Moreover, the difference in satisfaction between successful pessimists and successful optimists was not significant $(F \mathrm{~s}<1)$. This provides evidence that differentiates between 
depressives and pessimists. The pessimists are not simply prone to lower evaluations of their performance, or to a generally "gloomy" outlook compared to the rosy "glow" of the success optimists.

\section{DISCUSSION}

The present study provides support for the hypothesized strategy of defensive pessimism. The results clearly show that there are differences in level of expectation that we were able to predict by asking people well in advance of a task how they typically approach risky academic situations. This is the case even though both groups reported having done well in the past, and even though both groups performed at the same ability level on the task.

The predicted differences in cushioning efforts, evidenced by post hoc cognitive work, were also found. The optimists reported feeling significantly less in control in the failure condition than in the success condition, conforming to the "typical" attributional egotism pattern. Pessimists, however, did not demonstrate attributional egotism yet were just as satisfied (or dissatisfied) as the optimists. It therefore seems that the pessimists' initial lowered expectations are serving to cushion the impact of the subsequent failure feedback. The initially pessimistic structure does not, however, interfere with the enjoyment of success. The pessimists are just as satisfied with success feedback as the optimists. This is in contrast to what one would expect of depressives, who would not tend to feel satisfied with success feedback (Kuiper, 1978).

There is considerable debate among workers in social cognition about whether cognitive "biases" such as those included in the "illusory glow" are properly considered as motivational or informational (see Greenwald, 1982; Nisbett \& Ross, 1980). We began by contending that the strategies of defensive pessimism and "illusory glow" optimism could both be understood as motivated by the desire to maintain self-esteem and competence beliefs. Although this contention is not explicitly tested by this experiment, our results do strengthen the argument that these strategies are motivated and not simply information-processing biases. That is, we found clear differences in strategies between two groups with similar (high) performance histories, as indicated by their GPAs. Moreover, from the prescreening we chose only those subjects who acknowledged their past successes, thus reducing any "selective memory" bias. In addition, there was no difference in actual performance between the pessimists and optimists in either the success or failure condition. It is therefore difficult to ascertain a potential basis for differences in expectations using an argument based purely on information processing. One 
cannot assume that defensive pessimists simply have an overall tendency to see the "darker side" of things because of bad past experience. Furthermore, unlike depressives, pessimists are not reporting overall lower performance and satisfaction, especially in the success condition - their lack of "illusory glow" is not equivalent to the murky perceptions of depressives. However, our assumption is that the defensive pessimists are more fearful of failure in this situation than are the optimists; they are thus motivated to construct the "problem" presented by the situation in a different way. In fact, data gathered using a thought-listing procedure, where prescreened subjects imagined their thoughts and feelings the night before an exam, indicate that prescreened pessimists wrote significantly more sentences with a negative tone, more often mentioned feeling worried, anxious, or nervous, and more frequently anticipated a "worst case" outcome than did prescreened optimists (Showers \& Cantor, 1984).

From our "problem-solving" perspective, emphasizing different goals that underlie strategic behavior, we can parsimoniously account for the observed differences. Subjects using the defensive pessimist strategy were faced with the conflicting goals of wanting to avoid the risk of failure and wanting to achieve success. Using the concept of a strategy, it is possible to understand how setting low expectations can function defensively, and free the individual to construe the situation is a more motivating light.

Much of the information bias argument against motivational explanations is based on the assumption that the information gathered and processed in a situation is biased systematically by the expectations of the perceiver (Tetlock \& Levi, 1982). Our argument is that it is precisely in setting expectations before entering a situation that motivational influences can be observed in the case of defensive pessimism. The defensive pessimist strategy seems to be acting as a form of "natural" cognitive therapy for those using it. Faced with a threatening situation, the individual needs to be able to overcome the immobilization caused by a fear of failure that conflicts with the desire to achieve success. In order to act effectively, the individual structures the situation by "playing through" bad outcomes and thus controlling anxiety (Kuhl, 1984). This then should serve to reduce the conflict and motivate the individual to expend the effort necessary for success. The individual, in this situation, may be acting much as a cognitive therapist might with a patient in a similar situation. That is, the defensive pessimism systematically restructures the situation in order to better utilize the problem-solving skills he has available; he is thus able to overcome debilitating anxiety and focus on the task (Goldfried, 1979; Meichenbaum, 1977).

Continued investigation of the use of cognitive strategies such as defensive pessimism could have potential therapeutic applications, as the effectiveness of different strategies used over time or in different situations 
becomes clear (Kihlstrom \& Nasby, 1981; Turk \& Salovey, 1985). It may be, for example, that the "defensive" maneuver of setting low expectations ceases to work after a long series of good outcomes. After repeated success, an individual may not be able to get himself to believe in the exaggerated possibility of failure, at which point the fear of failure can no longer be converted into positive motivation. Alternatively, after a string of failures, the possibility of "taking control" may diminish: the low expectations that were previously defensive become merely realistic and thus do not cushion against subsequent failure. At this point, the defensive pessimist might begin to respond to risky situations in ways reminiscent of depression. The individual might become rigidly pessimistic in a given domain, to the extent that he is unable to overcome immobilization because he is convinced that it is impossible to "take control." The strategy might also become so habitual that it extends into all the relevant domains of an individual's life, at which time the sheer weight of all that negativism might prove overwhelming. Continued study of the conditions under which "normals" stop using these strategies flexibly may provide insight into the development of the negative thinking characteristic of depressives. For it is at that point that a motivating strategy may turn into a debilitating cognitive "trait."

\section{REFERENCES}

Alloy, L. B., \& Abramson, L. Y. (1979). Judgment of contingency in depressed and nondepressed students: Sadder but wiser? Journal of Experimental Psychology: General, 108, 441-485.

Atkinson, J. W., \& Litwin, G. H. (1960). Achievement motive and test anxiety conceived as motive to approach success and motive to avoid failure. Journal of Abnormal and Social Psychology, 60, 52-63.

Cantor, N. (1984). Social intelligence and life tasks. Invited paper presented at the 56th Annual Meeting of the Midwestern Psychological Association, Chicago.

Cantor, N., \& Kihlstrom, J. F. (1985). Social intelligence: The cognitive basis of personality. In P. Shaver (Ed.), Review of personality and social psychology. Beverly Hills: Sage.

D'Zurilla, T. J., \& Goldfried, M. R. (1971). Problem solving and behavior modification. Journal of Abnormal Psychology, 78, 107-128.

Goldfried, M: R. (1979). Anxiety reduction through cognitive-behavioral intervention. In P. C. Kendall \& S. D. Hollon (Eds.), Cognitive-behavioral interventions: Theory, research, and practice. New York: Academic Press.

Goldfried, M. R., Padawer, W., \& Robbins, C. (1984). Social anxiety and the semantic structure of heterosocial interactions. Journal of Abnormal Psychology, 93, 87-97.

Greenwald, A. G. (1980). The totalitarian ego: Fabrication and revision of personal history. American Psychologist, 35, 603-618.

Greenwald, A. G. (1982). Ego-task analysis: An integration of research on ego-involvement and self-awareness. In A. Hastorf \& A. Isen (Eds.), Cognitive social psychology. New York: Elsevier.

Higgins, E. T., McCann, C. O., \& Fondacaro, R. (1982). The "communication game": Goaldirected encoding and cognitive consequences. Social Cognition, 1, 21-37. 
Jones, E. E., \& Berglas, S. (1978). Control of attribution about the self through self-handicapping strategies: The appeal of alcohol and the role of under-achievement. Personality and Social Psychology Bulletin, 4, 200-206.

Kelly, G. A. (1963). The psychology of personal constructs. New York: Norton. (Original work published 1955.).

Kihlstrom, J. F. (1984). Personality as social intelligence: Understanding structures and social interactions. Invited paper presented at the 56th Annual Meeting of the Midwestern Psychological Association, Chicago.

Kihlstrom, J. F., \& Nasby, W. (1981). Cognitive tasks in clinical assessment: An exercise in applied psychology. In L. Berkowitz (Ed.), Advances in experimental social psychology (Vol. 17). New York: Academic Press.

Kuhl, J. (1984). Volitional aspects of achievement motivation and learned helplessness: Toward a comprehensive theory of action control. In B. Mahrer (Ed.), Progress in experimental personality research (Vol. 13). New York: Academic Press.

Kuiper, N. A. (1978). Depression and causal attribution for success and failure. Journal of Personality and Social Psychology, 36, 236-246.

McFall, R. M. (1982). A review and reformulation of the concept of social skills. Behavioral Assessment, 4, 1-33.

Meichenbaum, D. (1977). Cognitive behavior modification: An integrated approach. New York: Plenum Press.

Mischel, W. (1973). Toward a cognitive social learning reconceptualization of personality. Psychological Review, 80, 252-283.

Nisbett, R., \& Ross, L. (1980). Human inference: Strategies and shortcomings of social judgment. Englewood Cliffs, New Jersey: Prentice-Hall.

Showers, C., \& Cantor, N. (1984). Optimism and defensive pessimism: Cognitive strategies for risky situations. Unpublished manuscript, University of Michigan.

Spivak, G., Platt, J. J., \& Shure, M. B. (1976). The problem solving approach to adjustment. San Francisco: Jossey-Bass.

Tetlock, P. E., \& Levi, A. (1982). Attribution basis: On the inconclusiveness of the cognitionmotivation debate. Journal of Experimental Social Psychology, 18, 68-88.

Turk, D. C., \& Salovery, P. (1985). Cognitive structures, cognitive processes, and cognitivebehavior modification: I. Client issues. Cognitive Therapy and Research, 9, 1-17.

Weiner, B. (1965). The effects of unsatisfied achievement motivation on persistence and subsequent performance. Journal of Personality, 33, 428-442.

Weiner, B., \& Kukla, A. (1970). An attributional analysis of achievement motivation. Journal of Personality and Social Psychology, 15, 1-20. 